UDC 004.896

\title{
AN APPROACH FOR VIRTUALIZED NETWORK SLICES PLANNING IN MULTISERVICE COMMUNICATION ENVIRONMENT
}

\author{
Larysa S Globa, Svitlana V. Sulima, Mariia A. Skulysh, Anastasiia S. Zhuravel \\ Institute of Telecommunication Systems \\ Igor Sikorsky Kyiv Politechnic Institute, Kyiv, Ukraine
}

Background. Nowadays we face a huge growth in traffic of mobile networks due to the increased usage of smartphones and other mobile devices. To overcome these challenges and improve the efficiency of the network telecom operators use the advanced architectural solutions. These solutions are based on the concept of network slices.

Objective. In this paper the improving of the efficiency of mobile networks by forming and mapping slices of multi-service communication network based on network functions virtualization (NFV) is considered as an effective approach to resolve the mentioned above issues.

Methods. In order to find the optimal organization of slices the modified algorithm was proposed and performed for several different thresholds of functional losses.

Results. The algorithm solves the task of services grouping by their similarity and defines functional costs for services provision with minimum functional losses. Number of slices and functional losses in accordance with various threshold values were considered.

Conclusions. The results showed the possibility to rationally allocate system resources, especially when comparing to the similar approach. The further researches will be dedicated to more detailed analysis of the proposed approach with the aim of defining the optimal threshold values of functional losses.

Keywords: mobile networks; network functions virtualization (NFV); slice; network slicing; 5G.

\section{Introduction}

There is a significant growth in traffic of mobile networks due to the increased use of smartphones, services differentiation and other factors. Modern telecommunication systems are built as complex networks that cover different types of devices integrated into a single complex and work under large flows and number of connections. Besides, the average number of signaling messages per user is up to $42 \%$ higher for LTE compared with HSPA [1].

The latest innovations in mobile telecommunication technologies and mobile terminals stimulate proliferation of various services with a wide range of requirements for latency, mobility and security among others [2]. Mobile operators are oriented on expansion of possible services like mobile TV and music services, and the Internet of Things.

Currently, mobile networks mainly provide services of voice and data transmission through the Evolved Packet Core (EPC) architecture. EPC is an architecture of a full IP network that serves all different types of services and user equipment (UE) such as smartphones and M2M devices. Nowadays there is a big demand for developing new services providing approaches that will cover programmability in accordance to the requirements of the final users and types of services.

To overcome these challenges and improve the efficiency of the network telecom operators use the advanced architectural solutions. Mentioned solutions are based on the concept of network slices and define them as logically isolated networks based on the virtual 5G devices, virtualization of access, transport and core network functions.

The mentioned researches are devoted to the improvement of the efficiency of mobile networks by forming and embedding slices of multi-service communication network based on NFV technology for which an approach of optimal virtualized network slices planning is suggested.

The paper is structured as follows. Section 2 contains state of the art analysis of slice planning problem. Section 3 introduces method for network slices forming, while Section 4 presents method for network slices embedding. Section 5 shows modeling results' analysis. Section 6 includes the summary and outlook on future work

\section{State of art}

EPC is developed basing on an architectural approach "for any case" to support all types of traffic that is processed similarly with core network elements such as SGW and 
PGW [2]. Centralized fixed architecture and complexity are factors that hinder the development of mobile networks. Besides, the redundancy of functionality makes the situation more complex. For example, MME is used in a system to manage mobility of the users in EPC, but not all user equipment (UE) need to support mobility (e.g., sensors of M2M interaction have fixed geographical location within the operational term).

The requirements of EPC development necessitate of rapid and flexible deployment of new various services. Besides, network load varies during the day, so according to the studies [3] $80 \%$ of the computing power of base stations and up to the half of the capacity of core network are unused. This results in a lower use of resources and a high level of energy consumption and reduces economic efficiency for network operators.

Disadvantages of current EPC can be summarized as follows [2]:

1. System architecture. It is neither able nor efficient to support a wide variety of services (especially with strict requirements) because of inflexibility.

2. Packages processing. Data packages are processed unnecessary by many network elements, this process occurs in the mobile networks in multiple locations (from the eNB, SGW to PGW). Many processes are duplicated in different functional elements.

3. Subscriber status. The same states of users are supported by several network elements.

4. Time to entry the market. Traditional network EPC has long deployment cycle through the hardware deployment.

5. Total costs. High capital and operational expenditure (CAPEX and OPEX).

The virtualization technology is widely used to solve these problems [4].

Network function virtualization (NFV) is described within the specifications of the European Telecommunications Standards Institute (ETSI). The NFV principle [5] is aimed to transform network architectures by implementing network functions in software that can run on standard hardware platform. The network function is a functional unit within a network infrastructure, which has clearly defined external interfaces and clearly defined functional behavior. Examples of network functions are components in the network core LTE EPC, such as MME, HSS, etc. Thus, virtualized network function is an implementation of network function, which is deployed on virtual resources such as virtual memory and virtual CPU. Effective planning of slices location, their number and capacity for every network function on each slice still need more investigations.

NFV is closely related to other new technologies like SDN [6]. SDN is a network technology that separates the control plane from the underlying data plane and combines control functions in logically centralized controller.

In order to meet a wide range of requirements in the $5 \mathrm{G}$ era, various telecom organizations are working on the aforementioned issues. For example, NGMN uses the concept of "network slices" that establish dedicated virtual networks based on services using methods of network functions virtualization with slices and SDN.

Technologies like SDN and NFV are enabling a drastic change to take place in network architecture, allowing traditional structures to be broken devided into customizable elements that can be chained together programmatically to provide just the right level of connectivity, with each element running on the architecture of its choice. This is the concept of network slicing that will enable networks to be built in a way that maximizes flexibility [7].

Network slicing allows building (due to network architecture) future $5 \mathrm{G}$ networks, which cover the essential characteristics of scalability and flexibility, thus support the various scenarios and maintenance services. Network slice can be defined as a logically isolated network that includes $5 \mathrm{G}$ devices, network functions virtualization, transmission and core [8].

Researches in the field of network slicing are mainly concentrated on resource allocation problems and orchestration, such as [9], and the service-slice mapping policy they use is static.

Virtual network embedding (VNE) Problem [10] received considerable interest in recent years. This problem is also considered in works [11], [12], but these works do not cover specific environment where coexist physical units and units of virtualized services.

Researchers in [13] present a model for resource allocation of network functions within NFV environments, focusing on a scenario where part of the network functions may be provided by dedicated physical hardware, and where part of the functions are provided using virtualized instances. However, the problem of determining the capacity of hosted network functions remained unresolved.

The slicing concept may be one of the key features of $5 \mathrm{G}$ networks; however, the resources of functional entities allocated to each slices are exclusive and isolated. Thus, the architecture "Slice-for-service", which allocates slices resources for each service to ensure the performance requirements, will lead to loss of multiplexing gain. In 
addition, operators have to create and manage a huge number of slices for different services that is why the operating costs also increase. An effective way of reducing operating costs is to create slices, where on each slice the group with similar network requirements are placed, thereby the total number of slices decrease [14].

Thus, the main question is "what is reasonable or optimal number of network slices". Although the bigger number of slices can lead to enormous costs for management and maintenance of slices, but limits can also create a bottleneck in terms of functionality [2].

In this paper the approach "Slice-to-group" and the method of slices planning are improved. The prototype of the proposed method is described in [14], but the improved mechanism of accounting the productivity cost allowed reducing the number of recalculations of network slices optimal number and reducing resources costs. This study also suggests a method that aims to determine the location and amount of resources allocated to each network function in each slice, i.e. network segment. The general approach to embedding virtualized network is expanded by determining the model of network functions allocation, including the concept of hybrid networks containing both physical devices that provide services and virtualized components, and proposing the binding of network function performance to the amount of resources allocated to it.

\section{Slice forming method}

The proposed method for forming services on slices is shown on Fig. 1. The method consists of the following four steps.

Step 1. Checking whether the service needs an isolated slice. If so, the selected slice should be prepared.

Step 2. If service allows combining with other services, "functional loss" $\left(w_{k}\right)$ is estimated of each slice. Each slice is modeled as $N_{k}\left(s_{k}, p^{N S_{k}}\right)(k=1,2 \ldots n)$, where $s_{k}$ is a set $m_{k} \subset M$ of services that are placed in slice $k$ (e.g., $\mathrm{M}=$ \{ubiquitous video, e-health ,...\}). $p^{N S}{ }_{k}$ is a system performance of slice, which consists of several parameters (such as latency, bandwidth and density of UE). So, $p^{N S_{k}}=\left[p^{N S}{ }_{k, 1}, p^{N S}{ }_{k, 2}, \ldots\right.$, $\left.p^{N S}{ }_{k, l}\right]$, and $l$ is a number of system performance parameters. In slice the performance requirements of service

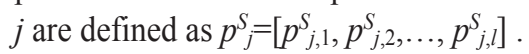

In this step the Service-slice Mapping Function (SMF) calculates $w_{k}$ on each slice as:

$$
w_{k}=\sum_{i=1}^{l} w_{k, i},
$$

$$
w_{k, i}=\left|p_{k, i}^{N S}-p_{k, j}^{S}\right|
$$

If the slice performance if different from the performance requirements of service, SMF calculates the difference between each parameter as "sub-functional losses $w_{k, i}$ ".

Step 3. The values $w_{k}$ for all slices are being sorted. Then the min $w_{k}$ is compared with the predetermined threshold $t h$. If it exceeds th, SMF provides new slices for service; otherwise, relative losses $r w_{k}$ are calculated suggesting that SMF locates service in slice $k$.

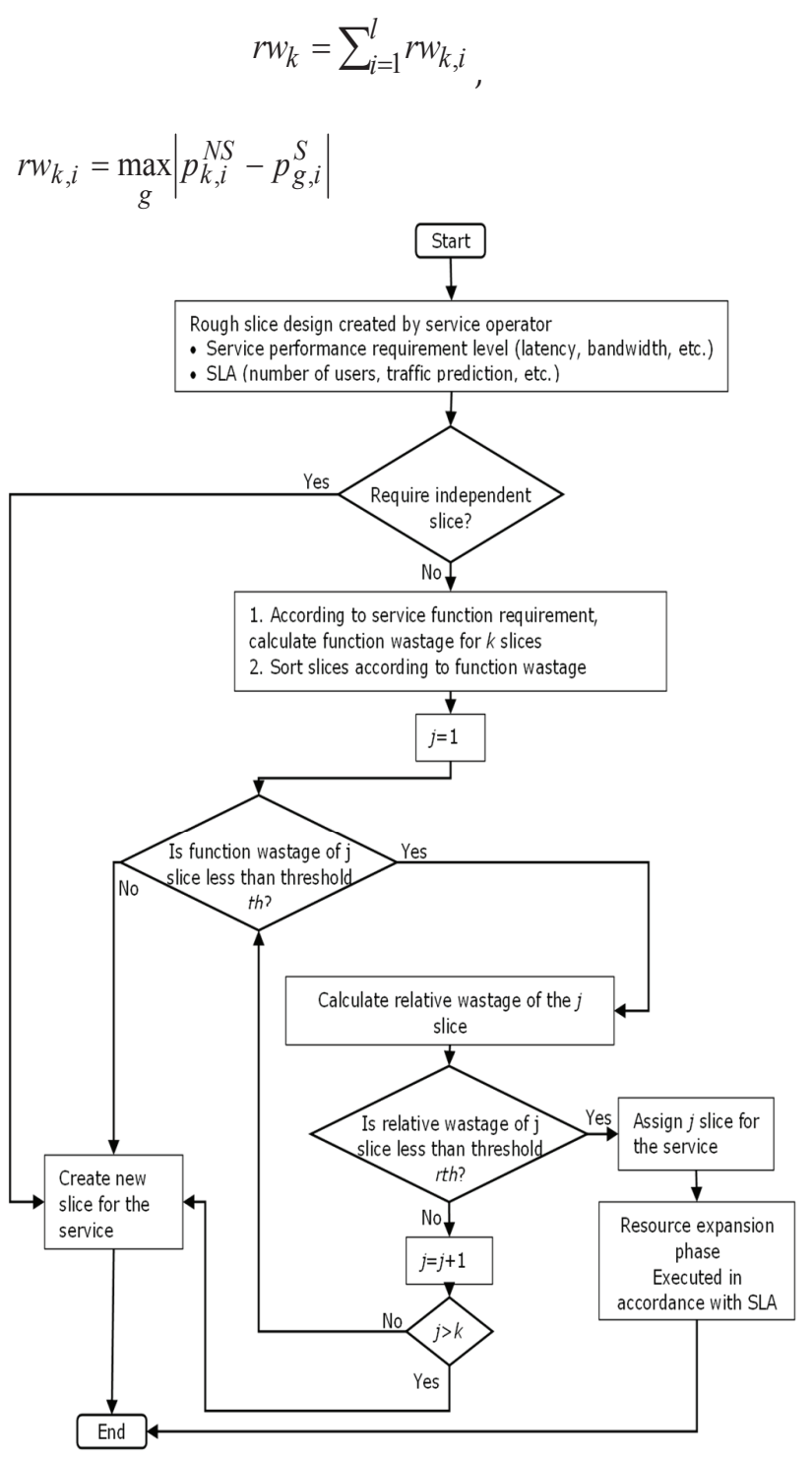

Fig. 1: The algorithm of slice forming method for services provision. 
Step 4. $r w_{k}$ is being compared with a predetermined threshold $r$ th. If it exceeds $r$ th, SMF repeats Step 3 for the next slice in the sorted set; otherwise, SMF allocates service in slice $k$. If none of the slices satisfies the boundary th or $r t h$, the new slice is created.

If SMF does not create new slice for service after the appropriate slice for service is selected, SMF calculates the required number of additional resources based on information of service traffic, number of subscribers, pattern of service traffic, and statistical multiplexing gain. Then SMF sends a request to management and orchestration system to expand the slice resources according to the result of calculation.

If for the EPC, th is equal to infinity, then all the services are multiplexed to one slice and functional losses are increasing, while the slice-per-service architecture, which provides individual slice for each service, has th equal to zero.

The method ensures that if the productivity of the slice increases, service functional losses will not exceed the thresholds.

In order to find the optimal organization of slices it is necessary to calculate the algorithm for several different thresholds of functional losses and compare it with the resulting gain of grouping services and operating costs. Then the possible formations of slices should be compared and the most effective one is chosen.

\section{Method of slices mapping}

Once the slices are formed, there is a stage of building and mapping virtualized network slices on underlying physical infrastructure while taking into account the availability of resources, load arrival rate and quality requirements related to the task of embedding virtual networks to physical network (Fig. 2). The proposed optimization model includes parameters and variables, which are shown in Table 1.

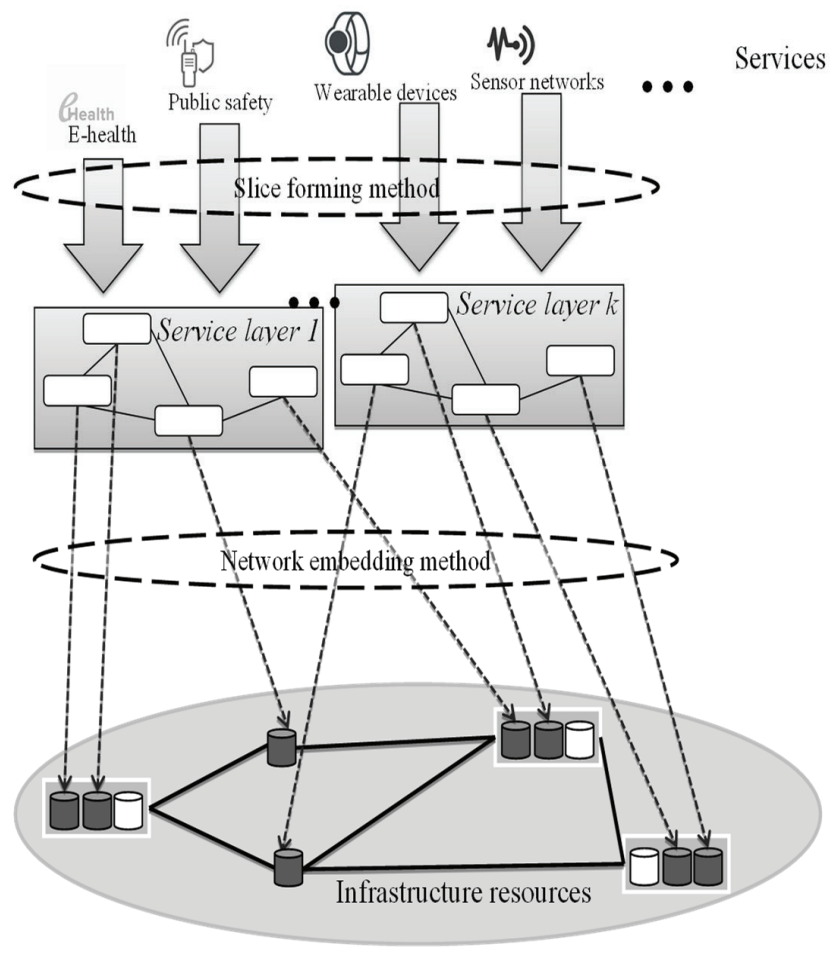

Fig. 2: Mapping of virtualized slices.

Table 1: Model parameters.

\begin{tabular}{|l|l|}
\hline \multicolumn{2}{|l|}{ Physical model } \\
\hline$G$ & the graph $G=(N, E)$ represents substrate network \\
\hline$N$ & $n \in N$ set of nodes include compute nodes $N^{c}$ and \\
\hline$E$ & $e^{=}\left(n_{1}, n_{2}\right) \in E$ is the set of edges within the network \\
\hline$\Gamma$ & $\gamma \in \Gamma$ types of resources \\
\hline$C_{n}^{\prime}{ }_{n}$ & $\gamma$ resource capacity of node $n$ \\
\hline$C E_{n 1, n 2}$ & bandwidth capacity of physical link $\left(n_{1}, n_{2}\right) \in E$ \\
\hline$L_{n 1, n 2}$ & transmission delay of physical link $\left(n_{1}, n_{2}\right) \in E$ \\
\hline $\mathbf{N F}$ model \\
\hline$\tau_{n}^{r}$ & processing delay of a physical NF r on node n \\
\hline $\mathbf{N S ~ m o d e l}$ \\
\hline$S F C$ & $c h \in S F C$ set of all service chains that must be \\
\hline$R_{c h}$ & $r_{c} \in R_{c h}$ is set of logical node of function chain $c h$ \\
\hline$L_{c h}{ }^{\max }$ & tolerance delay of a function chain $c h$ \\
\hline Variables \\
\hline$x^{r, c h}{ }_{n}$ & value is 1 when function chain $c h$ node $r$ is \\
\hline$F_{c h, e, r l,}$ & value is 1 when request of function chain $c h$ link \\
\hline$D^{r, c h}{ }_{\gamma}$ & integer specifies the amount of type $\gamma$ resource \\
\hline$D E_{c h, r l,}$ & integer specifies the amount of bandwidth used by \\
\hline
\end{tabular}


The network is represented as a graph $G=(N, E)$, consisting of a collection of nodes $N$ that represent physical network nodes and edges $E$ between these nodes. We assume that every edge $e=\left(n_{1}, n_{2}\right)$ has a capacity $C E_{n 1, n 2}$. A node can be any device in the network, such as computational nodes on which VMs can be deployed, or PNFs. Nodes $n \in N$ offer multiple types of resources, which are contained in the set $\Gamma$. Every node $n \in N$ has a resource capacity $C_{n}{ }_{n}$ for each of its offered resource types $\gamma \in \Gamma$. For every node, a usage cost $N C_{n}$, and a node resource use cost $N C_{n}{ }_{n}$ can be specified. The former cost is incurred whenever a node $n$ is used in an allocation, while the latter is incurred for every resource used on a node (e.g. a cost incurred for every CPU core used in a cloud node). These costs represent the cost of using the resource, and represent the cost of using cloud resources, energy use costs, licensing costs, opportunity costs, and possibly other costs. As some of these factors may vary over time, it is possible for these costs to vary over time, but it is assumed that they are constant during a single invocation of the resource allocation.

A collection SFC contains all service chains that must be allocated within the network. A service chain ch $\in S F C$ consists of a collection of NF requests. All requests in an SFC are grouped in the collection $R_{c h}$. The resource amount variable of a NF request $r$ of service chain $c h$ is represented by $D_{\gamma}^{r, c h}$, and is specified for all resources $\gamma \in \Gamma$. The network demand between requested NFs is represented by $D E_{c h, r 1, r 2}$ for any two requests $\left(r_{1}, r_{2}\right) \in R^{2}$ that are part of the $S F C$.

We define a binary decision variable, $x_{n}^{r, c h}$, that determines whether a request $r \in R$ is allocated on a node $n \in N$. If a service request may not be allocated on a given node, $x_{n}^{r}=0$ is added as a constraint, making it possible to restrict the nodes on which a service can be executed.

For each node $n \in N$, virt $n$ is a binary parameter that indicates whether the node $n$ is virtual, where $n \in N^{c}$, phys ${ }_{n}{ }^{j}$ - binary parameter that indicates whether node $n$ is a featured hardware unit of a function $j \in N F$, where $n \in N^{p}$. Optimization problem is formulated as follows:

Objective:

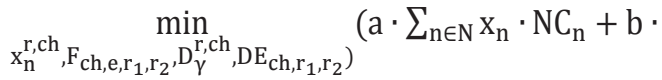

$\sum_{\mathrm{n} \in \mathrm{N}} \sum_{\gamma \in \Gamma} \sum_{\mathrm{ch} \in \mathrm{SFC}} \sum_{\mathrm{r} \in \mathrm{R}_{\mathrm{ch}}}\left(\operatorname{virt}_{\mathrm{n}} \cdot \mathrm{x}_{\mathrm{n}}^{\mathrm{r}, \mathrm{ch}} \cdot \mathrm{D}_{\gamma}^{\mathrm{r}, \mathrm{ch}}+\right.$ phys $_{\mathrm{n}}{ }^{\mathrm{r}}$.

$\left.\mathrm{x}_{\mathrm{n}}^{\mathrm{r}, \mathrm{ch}}\right) \cdot \mathrm{NC}_{\mathrm{n}}^{\gamma}+\mathrm{c} \cdot \sum_{\left(\mathrm{n}_{1}, \mathrm{n}_{2}\right) \in \mathrm{E}} \mathrm{NC}_{\left(\mathrm{n}_{1}, \mathrm{n}_{2}\right)}^{\mathrm{band}} \cdot$

$\sum_{\mathrm{ch} \in \mathrm{SFC}} \sum_{\left(\mathrm{r}_{1}, \mathrm{r}_{2}\right) \in \mathrm{R}_{\mathrm{ch}}} 2 \mathrm{~F}_{\mathrm{ch},\left(\mathrm{n}_{1}, \mathrm{n}_{2}\right), \mathrm{r}_{1}, \mathrm{r}_{2}} \cdot \mathrm{DE}_{\mathrm{ch}, \mathrm{r}_{1}, \mathrm{r}_{2}}+$ $\left.\mathrm{d} \sum_{\mathrm{ch} \in \mathrm{SFC}} \mathrm{FC}_{\mathrm{ch}} \cdot\left(1-\Phi^{\mathrm{ch}}\right)\right)$

$\max _{F_{\left(n_{1}, n_{2}\right), r_{1}, r_{2}, D E_{\left.c h, r_{1}, r_{2}\right)}}} \sum_{\left(n_{1}, n_{2}\right) \in E}\left(C E_{n_{1}, n_{2}}-\right.$
$\left.\sum_{c h \in S F C} \sum_{\left(r_{1}, r_{2}\right) \in R_{c h}}{ }^{2} F_{c h,\left(n_{1}, n_{2}\right), r_{1}, r_{2}} \cdot D E_{c h, r_{1}, r_{2}}\right)$
Subject to:

$\forall n \in N: \forall \gamma \in \Gamma: \sum_{c h \in S F C} \sum_{r \in R_{c h}}\left(\operatorname{virt}_{n} \cdot x_{n}^{r, c h} \cdot D_{\gamma}^{r, c h}+\right.$

$$
\text { phys } \left._{n}{ }^{r} \cdot x_{n}^{r, c h}\right) \leq C_{n}^{\gamma}
$$

$\forall c h \in S F C: \forall r \in R_{c h}: \sum_{n \in N} x_{n}^{r, c h}=1$

$\forall n \in N: \forall c h \in S F C: \forall r \in R_{c h}: x_{n}^{r, c h} \leq \operatorname{suit}_{n}^{r, c h}$

$$
\begin{gathered}
\forall c h \in S F C: \forall\left(r_{1}, r_{2}\right) \in R_{c h}{ }^{2}: \forall n \in \mathrm{N}: x_{n}^{r_{2}, c h}+ \\
\sum_{e \in E_{n}^{\text {out }}} F_{c h, e, r_{1}, r_{2}}=x_{n}^{r_{1}, c h}+\sum_{e \in E_{n}{ }^{\text {in }} F_{c h, e, r_{1}, r_{2}}} \\
\forall c h \in S F C: \forall\left(r_{1}, r_{2}\right) \in R_{c h}{ }^{2}: \forall n \in \mathrm{N}: x_{n}^{r_{2}, c h}+ \\
\sum_{e \in E_{n}^{\text {out }}} F_{c h, e, r_{1}, r_{2}} \leq 1 \\
\forall \text { ch } \in S F C: \forall\left(r_{1}, r_{2}\right) \in R_{c h}{ }^{2}: \forall n \in \mathrm{N}: x_{n}^{r_{1}, c h}+ \\
\sum_{e \in E_{n}^{\text {in }}} F_{c h, e, r_{1}, r_{2}} \leq 1
\end{gathered}
$$

$$
\begin{array}{r}
\forall\left(n_{1}, n_{2}\right) \in \mathrm{E}: \sum_{c h \in S F C} \sum_{\left(r_{1}, r_{2}\right) \in R_{c h}}{ }^{2} F_{c h,\left(n_{1}, n_{2}\right), r_{1}, r_{2}} \\
D E_{c h, r_{1}, r_{2}} \leq C E_{n_{1}, n_{2}}
\end{array}
$$

$\forall c h \in S F C$ :

$$
\begin{gathered}
\sum_{r \in R_{c h}} \sum_{n \in N} x_{n}^{r, c h} \cdot\left(\operatorname{virt}_{n} \cdot \sum_{\gamma \in \Gamma} \frac{s_{\gamma}^{r}}{D_{\gamma}^{r, c h}}+\operatorname{phys}_{n}{ }^{r} \cdot \tau_{n}{ }^{r}\right)+ \\
\sum_{\left(r_{1}, r_{2}\right) \in R_{c h}}{ }^{2} \sum_{\left(n_{1}, n_{2}\right) \in E} F_{c h,\left(n_{1}, n_{2}\right), r_{1}, r_{2}} \cdot L_{n_{1}, n_{2}} \leq L_{c h}{ }_{\max }
\end{gathered}
$$

where $a, b, c, d$-weight coefficients;

$N C_{n}, N C_{n}^{\prime}, N C_{(n 1, n 2)}^{\text {band }}$ - node, resource and bandwidth cost; $F C_{c h}-c h$ service allocation failure cost.

The objectives of the model are to minimize the total cost of the service function chains allocations (1) and to leave more bandwidth on each physical link (2). The constraints are: (3) the available capacity constraint, (4) ensures that every network function shall be mapped only once, (5) ensures that network function can be mapped only on suitable nodes, (6) the flow conservation constraint, (7)-(8) to make sure there is no incoming flow in source nodes or outgoing flow in sink nodes, (9) the available bandwidth constraint, (10) the required latency constraint.

\section{Experimental study of the effectiveness of the proposed approach}

The proposed algorithm of forming services on the slices was modeled and evaluated in the Mathcad software package, and also the relationsh(i) between the threshold 
values and functional losses for 24 services with 4 parameters of system performance requirements was defined. The service parameters were generated randomly by uniformly distributed numbers.

Three thresholds were used: one, two, and three. To compare the proposed method of forming services on the slices with other approaches, few cases such as the traditional EPC (in case of an infinite threshold, which means that any type of service can be placed into slice) and service-per-slice (when threshold is equal to zero, i.e. only one type of service can be placed in one slice) were considered.

Number of slices and functional losses in accordance with various threshold values are shown in Fig. 3. As shown in the figure with the threshold growth algorithm reduces the number of slices. On the other hand the amount of functional loss increases with the threshold.

Experimental results are presented in Table 2.

The simulation results indicate that there is a tradeoff between the number of slices and functional loss. Accordingly, the proposed algorithm provides the network operator with tool of selecting threshold that balances the number of slices (i.e., satisfies the performance requirements for services) and consumption of resources.

The method was compared with the similar method proposed in [14], which shows possible functional loss reduce of in average of $13 \%$.

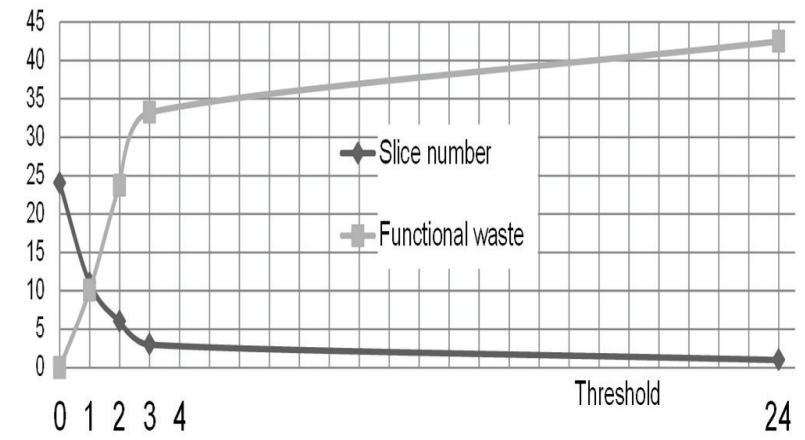

Fig. 3: Number of slices and functional costs depending on he threshold $t h$.

\begin{tabular}{|c|c|c|c|c|}
\hline & \multicolumn{2}{|c|}{ Approach suggested in [9] } & \multicolumn{2}{|c|}{ Improved approach } \\
\hline Threshold & $\begin{array}{c}\text { Number of } \\
\text { slices }\end{array}$ & Costs function & $\begin{array}{c}\text { Number of } \\
\text { slices }\end{array}$ & Costs function \\
\hline 0 & 24 & 0 & 24 & 0 \\
\hline 1 & 8 & 12,2 & 11 & 10,1 \\
\hline 2 & 4 & 24,2 & 6 & 23,8 \\
\hline 3 & 1 & 42,5 & 3 & 33,3 \\
\hline 24 & 1 & 42,5 & 1 & 42,5 \\
\hline
\end{tabular}

Table 2: Results of experiments.

\section{Conclusions}

Analysis of the principles of mobile networks construction revealed major development trends in telecommunication systems and challenges in their way. It is shown that technologies for dedicated virtualized networks designing that will be able to serve a variety of dynamic traffic services, supporting the specified performance requirements in the most cost-effective way will be the key technologies. For such systems, the configuration of the hybrid (physical-virtual) environment should be carefully organized.

The paper considers methods of forming and mapping network slices that will establish dedicated virtual networks that are based on services and grouped according to their functional similarity. To solve the problem of mapping slices of core multiservice mobile network the improved slice forming method is proposed. This method considers the costs for excessive allocation of resources based on a model of resources organizing and reduces the number of network configuration recalculations that allows achieving rational ratio of managing costs and network services quality of service. Also the model for resource allocation for determination of optimal amount of resources allocated to network functions in the slice is proposed. The model can be used in the management of network functions deployment in hybrid communication environment in order to minimize operator costs and improve quality of experience.

The method was evaluated using Mathcad modeling system. The results showed the possibility to rationally allocate system resources, especially when comparing to the similar approach.

The method can be used to control the deployment of multiservice virtualized networks on underlying physical 
network to minimize operator costs and improving quality of service.

In further researches the proposed methods will be analyzed in more detail, and selecting problem of threshold for the technical parameters that defines the functional costs in order to optimize the usage of resources and operating costs will be investigated.

\section{References}

[1] Chester Johnston (2012).Signaling is growing 50\% faster than data traffic, http://docplayer.net/6278117Signaling-is-growing-50-faster-than-data-traffic.html

[2] Malla Reddy Sama, Xueli An, Qing Wei, Sergio Beker (2016). Reshaping the mobile core network via function decomposition and network slicing for the 5G Era. DOI: 10.1109/WCNCW.2016.7552681.

[3] Liquid Core, http://networks.nokia.com/portfolio/liquidnet/liquidcore.

[4] Larysa Globa, Mariia Skulysh, Svitlana Sulima (2016). Method for resource allocation of virtualized network functions in hybrid environment. DOI: 10.1109/BlackSeaCom.2016.7901546.

[5] Margaret Chiosi (2012).Network Functions Virtualisation, https://portal.etsi.org/NFV/NFV White Paper.pdf

[6] M. Scharf, T. Voith, W. Roome, B. Gaglianello, M. Steiner, V. Hilt, and V. Gurbani (2012). Monitoring and abstraction for networked clouds. DOI: 10.1109/ICIN.2012.6376038.

[7] Network Slicing, https://www.ericsson.com/en/digitalservices/trending/network-slicing
[8] F. Z. Yousaf, M. Gramaglia, V. Friderikos, B. Gajic et al (2017). Network slicing with flexible mobility and QoS/QoE support for 5G Networks. DOI: 10.1109/ICCW.2017.7962821.

[9] Kai Han, Shengru Li, Shaofei Tang, Huibai Huang, Sicheng Zhao (2018). Application-Driven End-to-End Slicing: When Wireless Network Virtualization Orchestrates With NFV-Based Mobile Edge Computing, https://ieeexplore.ieee.org/abstract/document/8356658.

[10] N. Chowdhury et al. (2009). "Virtual Network Embedding with Coordinated Node and Link Mapping", pp. 783-91.

[11] Zhengfa Li, Zebin Lu, Shuhua Deng, Xieping Gao (2019). Customizable Function Chains: Managing Service Chain Variability in Hybrid NFV Networks, https://ieeexplore.ieee.org/stamp/stamp.jsp?tp=\&arnumb er=8672853.

[12] Zhengfa Li, Zebin Lu, Shuhua Deng, Xieping Gao (2018). A Self-Adaptive Virtual Network Embedding Algorithm Based on Software-Defined Networks, https://ieeexplore.ieee.org/document/8496853.

[13] Hendrik Moens, Filip De Turck (2016). Customizable Function Chains: Managing Service Chain Variability in Hybrid NFV Networks, https://ieeexplore.ieee.org/document/7491361.

[14] T. Shimojo, M. R. Sama, A. Khan, S. Iwashina (2017). Cost-efficient method for managing network slices in a multi-service $5 \mathrm{G}$ core network. DOI: 10.23919/INM.2017.7987451.

Глоба Л.С., Суліма С.В., Скуліш М.А., Журавель А.С.

Методики планування віртуалізованних мережевих слайсів в середовищі мультисервісної комунікації

Проблематика. На сьогоднішній день ми стикаємося з величезним зростанням трафіку мобільних мереж через збільшення використання смартфонів та інших мобільних пристроїв. Для подолання цих проблем і підвищення ефективності роботи мережі телеком оператори використовують передові архітектурні рішення. Ці рішення базуються на концепції мережевих слайсів.

Мета. В даній роботі розглядається ефективний підхід до вирішення зазначених вище проблем за допомогою поліпшення ефективності мобільних мереж шляхом формування та відображення слайсів мультисервісної мережі зв'язку на основі NFV.

Методи. Для знаходження оптимальнуого розміщення та організації слайсів був запропонований модифікований алгоритм і виконаний для декількох порогових значень функціональних втрат.

Результати. Алгоритм вирішує завдання групування сервісів за їх подібністю і визначає функціональні витрати на забезпечення сервісів 3 мінімальними функціональними втратами. Кількість слайсів і функціональні втрати були розглянуті у відповідності з різними пороговими значеннями.

Висновки. Результати показали можливість раціонального розподілу системних ресурсів, особливо при порівнянні 3 аналогічним підходом. Подальші дослідження будуть присвячені більш детальному аналізу запропонованого підходу 3 метою визначення оптимальних граничних значень функціональних втрат.

Ключові слова: мобільні мережі; віртуалізація мережевих функцій (NFV); слайс; мережевий слайсинг; 5G. 
Глоба Л.С., Сулима С.В., Скулиш М.А., Журавэль А.С.

Методики планирования виртуализованных сетевых слайсов в среде мультисервисной коммуникации

Проблематика. На сегодняшний день мы сталкиваемся с огромным ростом трафика мобильных сетей из-за увеличения использования смартфонов и других мобильных устройств. Для преодоления этих проблем и повышения эффективности работы сети телеком операторы используют передовые архитектурные решения. Эти решения базируются на концепции сетевых слайсов.

Цель. В данной работе рассматривается эффективный подход к решению указанных выше проблем посредством улучшения эффективности мобильных сетей путем формирования и отображения слайсов мультисервисной сети связи на основе NFV.

Методы. Для нахождения оптимального размещения и организации слайсов был предложен модифицированный алгоритм и выполнен для нескольких пороговых значений функциональных потерь.

Результаты. Алгоритм решает задачи группировки сервисов по их сходству и определяет функциональные расходы на обеспечение сервисов с минимальными функциональными потерями. Количество слайсов и функциональные потери были рассмотрены в соответствии с различными пороговыми значениями.

Выводы. Результаты показали возможность рационального распределения системных ресурсов, особенно при сравнении с аналогичным подходом. Дальнейшие исследования будут посвящены более детальному анализу предложенного подхода с целью определения оптимальных предельных значений функциональных потерь.

Ключевые слова: мобильные сети; виртуализация сетевых функций (NFV); слайс; сетевой слайсинг; $5 \mathrm{G}$. 